\title{
Fledgling begging and parental responsiveness in American dippers (Cinclus mexicanus)
}

\author{
Holly A. Middleton ${ }^{1,2)}$, David J. Green ${ }^{1)}$ \& Elizabeth A. Krebs ${ }^{3)}$ \\ ( ${ }^{1}$ Centre for Wildlife Ecology, Department of Biological Sciences, Simon Fraser University, \\ 8888 University Drive, Burnaby, BC V5A 1S6, Canada; ${ }^{3}$ Canadian Wildlife Service, 5421 \\ Robertson Road, Delta, BC 4VK 3N2, Canada)
}

(Accepted: 5 March 2007)

\begin{abstract}
Summary
In nestling birds, begging typically signals short-term hunger and is often used by parents to allocate food within a brood. Although young birds continue to beg long after nest departure less is known about the information content of begging and its influence on parental allocation patterns post-fledging. We examined the function of begging in fledgling American dippers (Cinclus mexicanus) and the corresponding provisioning rules and response of parents to variation in begging. We found no evidence that begging intensity correlated to short-term hunger. However, fledglings begged at higher intensities in a year with lower food abundance and reduced parental provisioning rates, suggesting that begging may reflect long-term condition. Parental provisioning was influenced by fledgling begging early in the post-fledging period. In the first week after fledging parents preferred to feed the fledgling begging most intensely when choosing between two young, and returned with food more rapidly if fledglings were begging at a higher intensity. In the second week, parents provisioned at a lower rate and no longer adjusted return times in response to variation in fledgling begging intensity. Although the decline in parental responsiveness is consistent with parent-offspring conflict we argue this does not appear to drive the timing of independence in juvenile dippers.
\end{abstract}

Keywords: parent-offspring conflict, post-fledging period, parental care.

\section{Introduction}

Young birds solicit resources from parents using conspicuous begging signals. Observational and experimental studies have shown a strong link between nestling begging and immediate hunger (Bengtsson \& Ryden, 1983;

\footnotetext{
2) Corresponding author's e-mail address: hollyamiddleton@hotmail.com 
Smith \& Montgomerie, 1991; Redondo \& Castro, 1992a; Price \& Ydenberg, 1995). For example, signal intensity typically increases when nestlings are deprived of food (Bengtsson \& Ryden, 1983; Smith \& Montgomerie, 1991) and decreases when nestlings are satiated (Bengtsson \& Ryden, 1983; Redondo \& Castro, 1992a). In nestlings, the correlation between hunger and signal intensity is argued to be maintained via energetic and predation costs (Godfray, 1995; Redondo \& Castro, 1992b; Haskell, 1994).

In addition to reflecting short-term hunger, begging could also reflect long-term patterns of food distribution and consequently function to communicate a chick's condition. Early observational studies suggested that begging may express long-term need (Ryden \& Bengtsson, 1980; Stamps et al., 1989). For example, in budgerigars (Melopsittacus undulatus), begging intensity was higher in last-hatched young, that received greater marginal benefit from a food item than did older siblings (Stamps et al., 1989). Several experimental studies have demonstrated that condition influences the structure (Sacchi et al., 2002) and intensity of begging calls (Price et al., 1996; Iacovides \& Evans, 1998). In fledglings, begging calls may be more likely to signal condition and long-term need because fledgling condition can influence subsequent survival (e.g., Heinsohn, 1991; Donnelly \& Sullivan, 1998).

Begging intensity can also be influenced by sibling competition. Consistent with this idea, begging is known to increase with brood size (Leonard et al., 2000), and varies with competitive ability (Leonard et al., 2000; Krebs, 2001; Neuenschwander et al., 2003) or relatedness (Briskie et al., 1994). However, the majority of studies on begging examine the behaviour of nestling birds. Sibling competition may be intensified during the postfledgling period if food is more limited, or reduced if some fledglings actively avoid competition. The extent to which sibling competition influences begging behaviour of fledglings is therefore unclear.

Begging intensity is frequently used by adult birds when allocating food in the nest. In most species, parents preferentially feed the nestling begging most conspicuously; i.e., the closest, loudest and/or largest nestling relative to nestmates (Redondo \& Castro, 1992a; Kilner, 1995; Leonard \& Horn, 1996; Price et al., 1996; Kolliker et al., 1998). Parents benefit from this allocation pattern if begging is an honest reflection of need, allowing food to be directed to the nestling that will benefit most from care (Godfray, 1991, 1995). 
As fledglings become older, parents and offspring may be in conflict over the timing of independence (Trivers, 1974). Fledglings often continue to solicit food from parents despite improved foraging efficiency and reduced energy requirements (Moreno, 1984; Langen, 1996). In response, parents can alter their behaviour in two ways. Parents may increase the time taken to return with the next food item, reducing the provisioning rate, and/or disregard variation in begging intensity (Davies, 1976). Further understanding of how provisioning rules change during the post-fledgling period may clarify the role of parent-offspring conflict in the transition to independence.

To understand begging strategies and parental allocation patterns of American dippers (Cinclus mexicanus) during the transition to independence, we examined the behaviour of parents and young during the post-fledging period. Dippers are well-suited to the study of post-fledging behaviour because they are restricted to linear territories along rivers or creeks permitting parent-offspring interactions to be easily monitored. Specifically we asked (1) whether begging reflects short-term or long-term need, (2) how begging influences parental allocation decisions and (3) how parental responses to begging change over the post-fledging period.

\section{Methods}

\section{Study species and study area}

We studied American dippers in the Chilliwack River watershed in southwestern British Columbia $\left(49^{\circ} 02^{\prime} \mathrm{N}\right.$ and $\left.121^{\circ} 04^{\prime} \mathrm{W}\right)$. Breeding birds were monitored at six sites along the main stem of the Chilliwack River and on four tributaries. The six river sites were each approximately $2 \mathrm{~km}$ long separated by $4-5 \mathrm{~km}$ of unmonitored stream, while accessible sections of each tributary ranged from 1 to $3 \mathrm{~km}$ in length. Additional details of the study area are provided in Morrissey (2004).

American dippers are obligate aquatic passerines that feed on aquatic insects and small fish in fast-flowing rivers and streams. Females lay 1-2 clutches containing 3-5 eggs. Females incubate and brood the nestlings but both parents contribute to provisioning of nestlings and fledglings (Kingery, 1996). Our study population is composed of both resident and migratory individuals. Residents hold year-round multi-purpose territories on the main stem of the river. Migrants move between wintering areas on the main stem 
of the Chilliwack River and breeding territories on higher elevation tributaries. Migration delays the onset of breeding by 1-2 weeks and as a consequence migrants are less likely to be double-brooded and have lower reproductive success (Morrissey, 2004).

\section{Monitoring of breeding}

The study was conducted from late February until mid-July of 2003-2005. Breeding adults were captured in mist nets and marked with a unique combination of three Darvic ${ }^{\circledR}$ colour bands and one USFWS aluminum band. All pairs were monitored throughout the breeding season from nest initiation (nest-building) until fledging (24-26 days after hatching). Ten to 14 days after hatching, nestlings were banded and weighed to the nearest $0.25 \mathrm{~g}$ using a spring balance. Territories were visited on a daily basis preceding the predicted fledge date (24-26 days after hatching) to determine the fledge date and the number of nestlings that fledged.

\section{Molecular sex determination}

At the time of nestling banding a blood sample (approx. $25 \mu \mathrm{l}$ ) was collected from the brachial vein. DNA was later extracted from the blood samples using a standard ammonium salt extraction. We determined fledgling sex using a DNA-based test employing PCR amplification of a section the avian CHD1 genes (CHD1-W and CHD1-Z) located on the avian sex chromosomes (Griffiths et al., 1998).

\section{Focal observations}

In 2003-2005 we attempted to make detailed observations on all brood members on the first five days after fledging and a further three times 6-8, 9-11 and 12-14 days after fledging. On average, individuals were observed 4 times. Sample sizes of each age varied as not all individuals could be located on each day and some fledglings died or left their natal territory before 14 days had elapsed. Focal fledglings were observed for approximately one hour on each observation day (mean: $56 \mathrm{~min}$, range: 20-115 min). We recorded the number of food deliveries made by each parent, whether a fledgling was alone or close to a sibling, and the begging intensity of the focal fledgling each time it was approached with food. Begging intensity was recorded using 
a four-point scale: (0) no vocal or visual response; (1) either a vocal response or a wing-flutter; (2) a vocal response with wing-flutter and/or crouching; and (3) loud, sustained vocal response, intense wing-beating, crouching, gaping, and facing the parent. When the focal fledgling was close $(<5 \mathrm{~m})$ to a sibling we also recorded the identity and begging score of the sibling. In 2005, we also recorded the position of the focal fledgling relative to its sibling when the parent landed on the riverbank (closest or furthest).

\section{Food availability}

In 2004 and 2005, we assessed invertebrate abundance within each territory 5-7 days post-fledging using the 5-rock sampling method (McCutchen, 2002). Briefly, sampling was conducted at five accessible locations where the breeding pair had been observed collecting prey. At each location, five fistsized rocks from the stream bed were placed in a shallow tub held above the water column and all detectable invertebrates were removed and preserved in a $95 \%$ ethanol solution. Surface area of sample rocks was determined by algebraic transformation of the volumetric displacement of the rock into surface area $\left(\mathrm{SA}=\mathrm{LOG}(\right.$ Volume $\left.) * 13.88^{3.6}\right)$. Samples were dried for 24 $\mathrm{h}$ in a food dehydrator and the sum of the dry mass per unit area from the five sample locations was used as an index of food abundance in the territory.

\section{Statistical analyses}

We analyzed the data using a mixed modeling approach because our data included multiple observations on the same individual from broods containing 2-5 fledglings. Provisioning and begging behaviour were initially explored by fitting mixed models to two dependant variables: total food delivery rate and mean begging intensity. Explanatory variables included year (2003-2005), fledge date, fledgling age, fledgling sex, whether the pair subsequently re-nested or not, brood size at observation age, and the percent of time spent $\leqslant 5 \mathrm{~m}$ from a sibling. We subsequently examined whether begging influenced (1) whether a focal fledgling was fed or not when parents chose between two siblings in close proximity and (2) the time taken to return to a focal fledgling with another food item. Explanatory variables included begging intensity (or relative begging intensity compared to a sibling), parental and fledgling sex, fledgling age (1-5 days after nest departure), fledge date, 
and year. We predicted that parental responses to begging intensity would change as fledglings approached independence so, for the latter analysis, we examined data from week 1 and week 2 after nest departure separately. These analyses were restricted to begging signals observed during the first half of each focal observation so that there was time for parents to return with the next food item.

Models examining continuous dependant variables were analyzed using the 'restricted maximum likelihood' (REML) procedure and dichotomous dependant variables were run using the Generalized Linear Mixed Model (GLMM) procedure using GENSTAT 5.4.1 for Windows (GENSTAT 5 Committee, 1997). Initially all mixed models identified individual and brood as random factors. However, brood was subsequently dropped as there was little variance associated with the random term (see Legge et al., 2001 for rationale). We fitted a full model including all main effects and relevant interaction terms. Final models were selected by systematically eliminating all non-significant interaction terms and then main effects until only significant terms remained. For continuous dependant variables, significance was determined using the change in deviance associated with dropping the term of interest from the final model. For dichotomous variables, significance was determined using the Wald statistic when the term of interest was the last term entered into the model. The change in deviance and the Wald statistic both approximate a chi-square distribution (Payne, 2006). Parental feeding rates and responses to begging (return times) were $\log _{10}$-transformed to ensure that statistical models conformed to assumptions regarding the normality and heteroskedasticity of residuals.

To examine how begging varied with short-term hunger, we compared the mean begging intensity of fledglings following long breaks between feeding events ( $>20 \mathrm{~min}$ ) and short breaks between feeding events ( $<4 \mathrm{~min}$ ) using a repeated measures ANOVA controlling for year. For each individual we also calculated standardized regression coefficients for the relationship between the time interval between feeding events and the subsequent begging intensity and tested whether these coefficients were significantly different from a null of zero. Since fledglings begin to disperse in the second week we only used data collected during the first five days after fledging to minimize any sampling biases. 


\section{Results}

\section{Interannual variation of dippers}

Fewer pairs initiated breeding in 2004 than in 2003 or 2005. Pairs that bred initiated breeding earlier in 2004 than in 2003 or 2005 (controlling for known differences in the timing of breeding by residents and migrants (Morrissey, 2004)). Brood sizes did not differ between years. Breeding pairs in 2004, despite starting to breed sooner, were no more likely to initiate a second brood than breeding pairs in 2003 or 2005, and produced a similar number of fledglings over the season (Table 1).

Invertebrate abundance during the post-fledging period was lower in 2004 than 2005 , perhaps explaining why the early onset to the breeding season in 2004 did not translate into higher reproductive success (Table 1). Although there was considerable variation among territories, mean invertebrate abundance during the post-fledging period was almost 2.5 times greater in 2005 than in 2004.

\section{Food delivery rates to individual fledglings}

Total food delivery rate to fledglings was highest in 2005 and lowest in 2004 (Table 1). Delivery rates varied with fledgling age, and declined significantly in the second week $\left(\chi^{2}=14.75, \mathrm{df}=7, p=0.04\right.$, Figure 1). Male and female fledglings were fed at the same rate $\left(\chi^{2}=0.06, \mathrm{df}=1, p=0.80\right)$. Food delivery rate was not influenced by brood size $\left(\chi^{2}=4.4\right.$, df $=4$, $p=0.35$ ), the amount of time the focal individual was located within $5 \mathrm{~m}$ of a sibling $\left(\chi^{2}=0.88, \mathrm{df}=1, p=0.35\right)$, or whether a pair attempted a subsequent nesting attempt $\left(\chi^{2}=0.91, \mathrm{df}=1, p=0.63\right)$.

What factors influence fledgling begging intensity?

Fledglings typically begged only in the presence of an adult. Mean begging intensity during focal observations was not influenced by the sex of the fledgling $\left(\chi^{2}=0.48, \mathrm{df}=1, p=0.49\right)$, fledgling age $\left(\chi^{2}=7.6, \mathrm{df}=\right.$ $7, p=0.37)$ or hatch date $\left(\chi^{2}=0.01, \mathrm{df}=1, p=0.92\right)$. Mean begging intensity also did not increase as the amount of time a fledgling was in close proximity to a sibling increased $\left(\chi^{2}=2.13, \mathrm{df}=1, p=0.14\right)$.

Mean begging intensity was strongly influenced by year (Table 1 ), but not by food abundance on individual territories five days after fledging $\left(\chi^{2}=\right.$ 


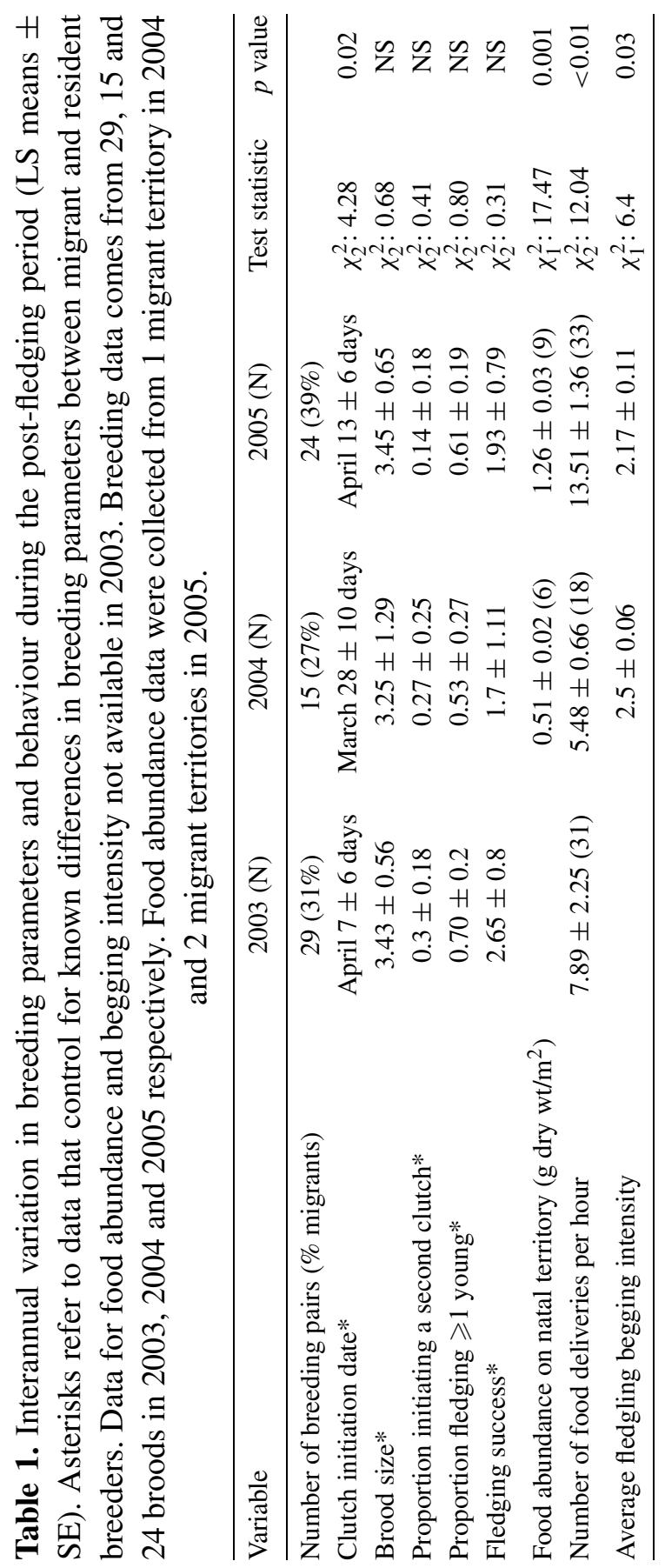




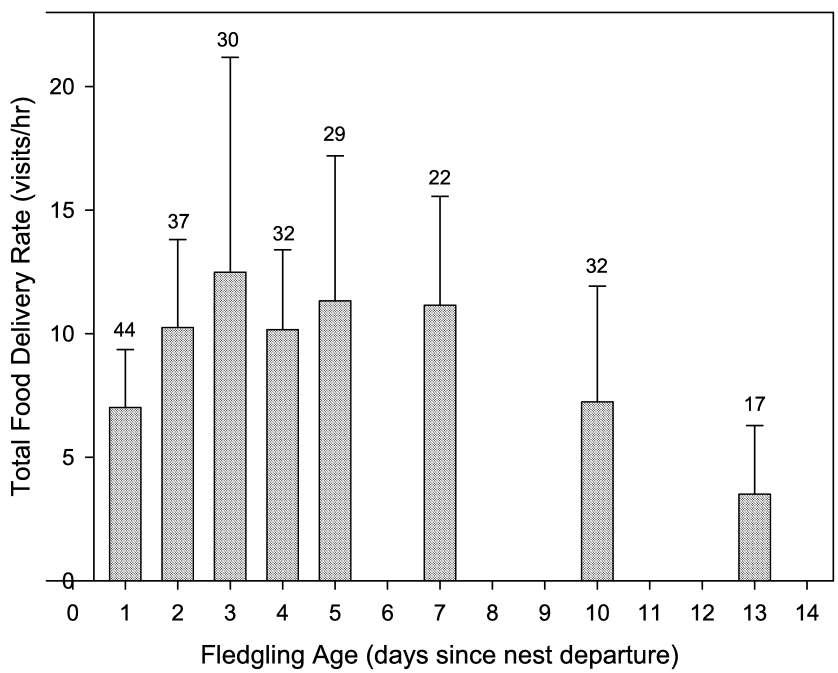

Figure 1. Relationship between fledgling age (number of days since nest departure) and parental feeding rate (total deliveries by the pair/h). The bars show the mean $\pm \mathrm{SE}$. The numbers above the bars show the number of fledglings observed at each time interval and represent data from 61 fledglings and 28 broods monitored between 2003 and 2005 . Untransformed data are presented although analyses were conducted on log-transformed values.

$0.04, \mathrm{df}=1, p=0.84)$. Begging intensity was higher in 2004, the year with lower feeding rates, compared with 2005 (Table 1) suggesting that begging intensity was influenced by longer-term patterns of food availability.

To investigate the influence of short-term hunger on begging we examined how begging intensity changed with time between feeding visits. We found little evidence that short-term hunger influenced begging intensity in the first five days after nest departure. First, although mean begging intensity was higher in 2004 than 2005, an individual's begging intensity was not influenced by whether the interval between feeding visits were short or long (year effect: $F_{1,38}=20.33, p<0.001$; time since last feed: $F_{1,38}=0.29$, $p=0.59$; year by time since last feed interaction: $F_{1,38}=0.77, p=$ 0.39; Figure 2). Second, coefficients from regressions relating the begging intensity of an individual to the time interval since the last food delivery did not differ from zero (mean standardized regression coefficient $\pm \mathrm{SE}=$ $-0.01 \pm 0.01, p=0.52$ ). Regression coefficients did not differ significantly from zero in either 2004 (mean $r=-0.02, t=-1.34, p=0.19$ ) or 2005 (mean $r=0.02, t=1.44, p=0.18$ ) suggesting that begging intensity was not influenced by time elapsed between feeding events. 


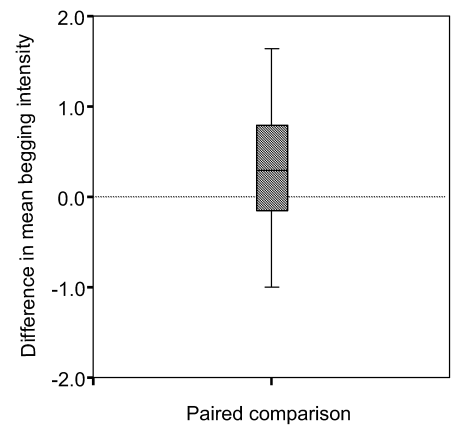

Figure 2. Box plots showing differences between mean begging intensities of individuals following short $(<4 \mathrm{~min})$ and long $(>20 \mathrm{~min})$ gaps between feeding events. The median is at the mid line, the box contains $50 \%$ of data and $95 \%$ of the data is bound by the whiskers. Observations were conducted on a total of 37 individuals from 17 broods monitored in 2004 and 2005.

\section{Parent provisioning rules}

In the first week, when given a choice between feeding two fledglings, both males and females fed the fledgling begging at the highest intensity (begging intensity effect: $\chi^{2}=51.2, \mathrm{df}=1, p<0.001$, parent sex effect: $\chi^{2}=0.1$, $\mathrm{df}=1, p=0.92$, parent sex by begging intensity interaction: $\chi^{2}=0.01, \mathrm{df}$ $=1, p=0.92$; Figure 3). Neither the sex of the focal chick nor the sex of the other dyad member influenced whether the focal fledgling was fed (focal sex effect: $\chi^{2}=0.10$, df $=1, p=0.75$, sibling sex effect: $\chi^{2}=0.03$, $\mathrm{df}=1, p=0.86$, focal sex by sibling sex interaction: $\chi^{2}=0.001, \mathrm{df}$ $=1, p=0.98$ ). In 2005, when more detailed data were collected on chick proximity, parents were also more likely to feed the fledgling that was closest to them when they landed on the riverbank (closest: $0.62 \pm 0.01$, furthest: $0.35 \pm 0.04 ; \chi^{2}=6.4, \mathrm{df}=1, p=0.01$ ) but controlling for proximity did not alter the result that begging intensity influenced provisioning decisions $\left(\chi^{2}=6.5, \mathrm{df}=1, p=0.01\right)$.

In the first five days post-fledging, parents returned with food more quickly when fledglings begged at the highest intensity (begging intensity effect: $\chi^{2}=7.42$, df $=2, p=0.03$, parent sex by begging intensity: $\chi^{2}=0.60, \mathrm{df}=2, p=0.74$; Figure 4). Males and females did not differ in their response times $\left(\chi^{2}=2.09, \mathrm{df}=1, p=0.15\right.$, all interactions with parent sex: $p>0.10)$. The return time of both sexes tended to be longer in 2004 than in $2005\left(\chi^{2}=3.40, \mathrm{df}=1, p=0.07\right)$. Return time also declined from day 1 to day 5 post-fledging $\left(\chi^{2}=19.10, \mathrm{df}=4, p=0.001\right)$. 


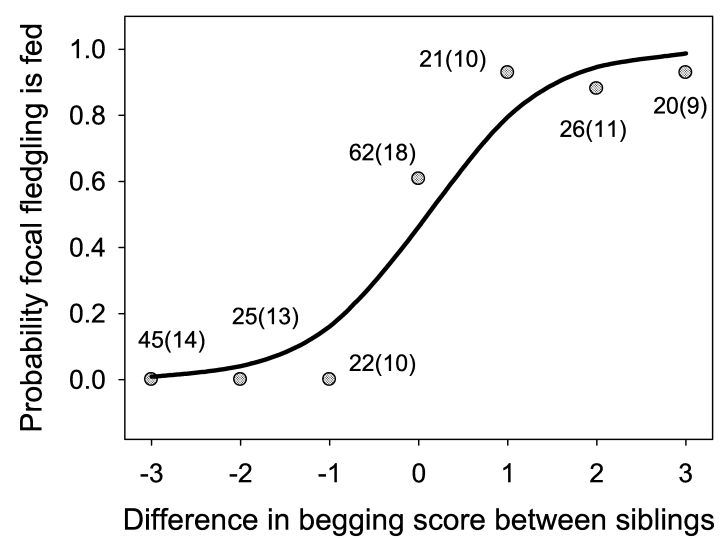

Figure 3. Relationship between the relative begging intensity of a fledgling compared to its nearby sibling and the probability of being fed. Positive values represent individuals begging at a higher intensity than its sibling. Negative values represent individuals begging at a lower intensity than its sibling. The curve shows the prediction from a logistic mixed model. The numbers show the number of observations (number of focal individuals) at each point and represent data from 37 individuals and 17 broods.

A

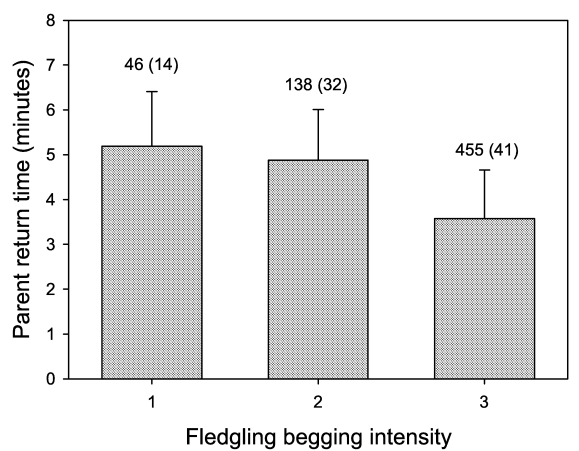

B

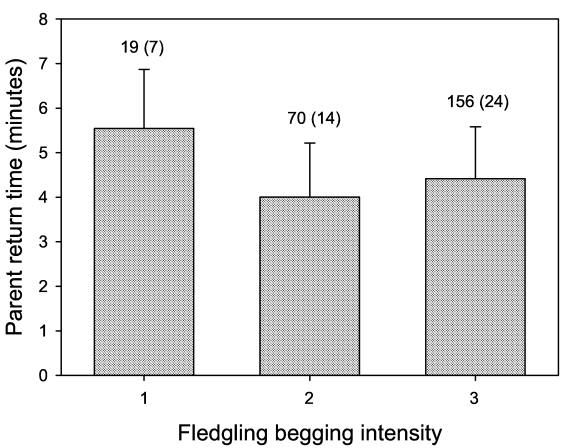

Figure 4. Relationship between the begging intensity of a fledgling and the time taken for a parent to return with the next food item in A) in the first 5 days after nest departure and B) the second week after nest departure. Bars represent LS mean \pm SE after controlling for the significant effects of year (in A) and parent sex (in B). The numbers above the bars show the number of observations (number of individuals). In A data comes from 39 individuals from 16 broods. In B data comes from 22 individuals from 11 broods. Untransformed data are presented although analyses were conducted on log-transformed values.

In the second week after fledging, parents no longer responded to higher begging intensity by returning more quickly $\left(\chi^{2}=1.45, \mathrm{df}=2, p=0.69\right)$. 
Parents took longer to return with food in the second week in 2004 than in $2005\left(\chi^{2}=11.41, \mathrm{df}=1, p=0.001\right)$. Females took less time to return than males in week two but the two parents did not differ in how they responded to age, sex, or begging behaviour of their fledglings (females: LS mean $\pm \mathrm{SE}$ $=3.10 \mathrm{~min} \pm 1.27$, males: $\mathrm{LS}$ mean $\pm \mathrm{SE}=4.88 \mathrm{~min} \pm 1.17 ; \chi^{2}=4.15$, $\mathrm{df}=1, p=0.04$ ) (parent sex by begging intensity: $\chi^{2}=0.41, \mathrm{df}=5$, $p=0.94)$.

\section{Discussion}

Studies of nestlings show that begging typically reflects the short-term need or hunger level of an individual (e.g., Bengtsson \& Ryden, 1983; Smith \& Montgomerie, 1991). In contrast to these studies, we found that begging by fledgling dippers did not reflect short-term hunger but was correlated with interannual variation in parental feeding rates. This suggests that begging reflects longer-term need in fledgling dippers. Nevertheless, parents responded to variation in the intensity of begging in the first week after fledging. Parents both returned more quickly and were more likely to allocate food to fledglings begging at a higher intensity. Parents reduced provisioning rates and became less responsive to fledgling begging intensity in the second week after fledging, suggesting there was some conflict over the timing of independence.

\section{Fledgling begging signals: do they reflect short or long-term need?}

We found little evidence that the time interval between feeding events influenced begging in fledgling American dippers suggesting that begging intensity does not reflect short-term hunger. This is in contrast with most studies of nestlings where begging is positively correlated with short-term hunger (Bengtsson \& Ryden, 1983; Smith \& Montgomerie, 1991; Redondo \& Castro, 1992a). Begging may be more tightly linked to short-term hunger in nestlings because of the higher metabolic costs associated with growth and thermoregulation. At the fledgling stage, a decreased growth rate and the ability to supplement provisioning with self-foraging may allow them to stay satiated for longer periods of time (Marchetti \& Price, 1989). Potentially, the time lags between feeding events in our study could have been too short to induce hunger and influence begging intensity in fledgling dippers. However, 
we believe this is unlikely because begging intensity varied considerably, gaps in feeding were defined based on the observed variation, and we could detect neither a step function nor a graded response relating gaps in feeding to fledgling begging intensity.

Begging has been linked to long-term condition of nestlings in a few studies (Price et al., 1996; Iacovides \& Evans, 1998; Sacchi et al., 2002). For example, Price et al. (1996) showed that nestling yellow-headed blackbirds (Xanthocephalus xanthocephalus) in poor condition begged at higher intensities than nestlings in superior condition. Begging by fledglings may be more likely to reflect long-term food distribution patterns since fledgling condition is closely linked to juvenile survival (e.g., Heinsohn, 1991; Donnelly \& Sullivan, 1998). We believe that the interannual variation in begging intensity in fledgling dippers may result from variation in fledgling condition. In our study, invertebrate abundance was lower in 2004 than in 2005, and parents delivered significantly less food to fledglings. Unfortunately, we have no direct measure of fledgling condition during the period we measured food abundance or delivery rates. However, food abundance has been linked to nestling condition and begging intensity in tree swallows; begging intensity of nestlings was higher at a site with lower food abundance (Hussell, 1988). In our study fledgling dippers begged more intensely in 2004 when food abundance and feeding rates were low suggesting that begging intensity is likely to reflect condition. Further exploration of the impact of fledgling condition and growth rate on begging intensity is therefore warranted.

\section{Influence of sibling competition on begging}

In many species, social context can influence begging. Begging of nestlings intensifies with increasing brood size (Leonard et al., 2000) and relative competitive ability (Smith \& Montgomerie, 1991; Price \& Ydenberg, 1995; Leonard \& Horn, 1998; Krebs, 2001). Begging of fledglings can also be influenced by social context. For example, great tit (Parus major) fledglings in dyads begged at higher intensities and received more food than when they were alone (Sasvári, 1990). In contrast, the begging intensity of fledgling dippers did not increase when they spent more time in dyads despite the fact that parents preferentially fed the fledgling begging at the highest intensity. This may be in part because the presence of a sibling did not alter the amount of food an individual obtained. 
Response of adults to begging

In the nest, parents can respond by allocating food or by adjusting their delivery rate in response to variation in begging intensity. Parents generally feed the closest, loudest and/or largest nestling (Leonard et al., 1994; Kilner, 1995; Smiseth et al., 1998, 2003). Experimental studies also suggest that parents increase provisioning rates (tree swallow (Tachycineta bicolor): Leonard \& Horn, 1996, 1998, 2001b; crimson rosella (Platycercus elegans): Krebs, 2000; grey-headed albatross (Thalassarche chrysostoma): Phillips \& Croxall, 2003) or reduce inter-trip intervals (Henderson, 1975; Bengtsson \& Ryden, 1983; Hussell, 1988; Stamps et al., 1989; Smith \& Montgomerie, 1991) in response to increasing begging intensity. We observed similar parental responses to the begging of fledgling American dippers. The begging intensity of fledglings influenced both allocation decisions and return times of male and female dippers early in the post-fledging period. This is consistent with cues found to influence allocation decisions in other studies of fledgling birds. For example, Sasvári (1990) and Smith et al. (2005) found that great tit and common tern (Sterna hirundo) parents, respectively, preferred to allocate food to fledglings begging at the highest intensity.

Parents and offspring interactions are expected to change over the postfledging period as a result of conflicts over the timing of independence (Trivers, 1974). Davies (1978) suggested that parents may promote independence by decreasing their provisioning rates or reducing their responsiveness to offspring solicitation. Parents may also promote independence by behaving aggressively towards young (Sullivan, 1988; Leonard et al., 1990). Declines in parental provisioning rates have been shown to decrease prior to independence in many species (e.g., spotted flycatcher Muscicapa striata Davies, 1976; great tit Davies, 1978). Reduced responsiveness to variation in begging intensity late in the post-fledging period has been documented less often (but see Moreno, 1984). In our study, parents reduced both the provisioning rate and stopped being responsive to variation in begging intensity in the second week of the post-fledging period. American dipper parents may therefore encourage independence in older fledglings both by reducing provisioning rate and reducing their response to high intensity begging.

Although parents were less responsive to begging and decreased their feeding rates in the late post-fledging period, there are two reasons that changes in parental behaviour appear unlikely to determine the timing of 
independence in American dippers. First, $18 \%$ of fledglings leave their natal territory 6 to 8 days after nest departure when parents are still provisioning at a high rate (H. Middleton, unpublished data). Secondly, there was no evidence of parental aggression towards fledglings at any point in the postfledging period. The absence of aggression, and the departure of young prior to reduced feeding rates, suggests there are additional cues determining the timing of independence by the young.

In summary, this study shows that begging intensity of American dippers during the post-fledging period is not related to short-term hunger, in contrast to most studies conducted during the nestling period. We found that begging intensity was higher in a year when parental provisioning rate is low suggesting that begging is likely to be related to the condition of dipper fledglings. Parents allocated food and adjusted provisioning behaviour in response to the relative begging intensity of their fledglings early in the post-fledging period. As predicted, parents altered their response to fledgling begging signals during the transition to independence. However, whether changes in parental behaviour during the transition to independence determine the dispersal decisions of juvenile dippers remains unclear.

\section{Acknowledgements}

We would like to thank D. Lissimore, M. Bandura, J. Preston and E. Gillis for their tireless effort in the field, the Department of Fisheries and Oceans Cultus Lake Salmon Research lab for providing us with accommodation, and Chilliwack River Rafting Adventures for helping us to access some nests. We would also like to thank Ron Ydenberg for helpful comments on earlier drafts. This research was funded by a Science Horizons Youth Internship, two Simon Fraser University Graduate Research Fellowship and support from the Centre for Wildlife Ecology to HAM, and an NSERC discovery grant to DJG.

\section{References}

Bengtsson, H. \& Ryden, O. (1983). Parental feeding rates in relation to begging behavior in asynchronously hatched broods of the great tit, Parus major. - Behav. Ecol. Sociobiol. 12: 243-251

Briskie, J.V., Naugler, C.Y. \& Leech, S.M. (1994). Begging intensity of nestling birds varies with sibling relatedness. — Proc. R. Soc. Lond. B 258: 73-78.

Davies, N.B. (1976). Parental care and transition to independent feeding in the young spotted flycatcher (Aves-Moticillidae). - Behaviour 59: 280-295.

Davies, N.B. (1978). Parental meanness and offspring independence: an experiment with hand-reared Great Tits Parus major. — Ibis 120: 509-514. 
Donnelly, R. \& Sullivan, K.A. (1998). Foraging proficiency and body condition of juvenile American dippers. - Condor 100: 385-388.

Godfray, H.C.J. (1991). Signalling of need by offspring to their parents. — Nature 352: 328330.

Godfray, H.C.J. (1995). Signaling of need between parents and young: parent-offspring conflict and sibling rivalry. - Am. Nat. 146: 1-24.

Griffiths, R., Double, M.C., Orr, K. \& Dawson, R.J.G. (1998). A DNA test to sex most birds. - Mol. Ecol. 7: 1071-1075.

Haskell, D. (1994). Experimental evidence that nestling behaviour incurs a cost due to nest predation. - Proc. R. Soc. Lond. B 257: 161-164.

Heinsohn, R.G. (1991). Slow learning of foraging skills and extended parental care in cooperatively breeding white-winged choughs. - Am. Nat. 137: 864-881.

Henderson, B.A. (1975). Role of the chick's begging behavior in the regulation of parental feeding behavior of Larus glaucescens. - Condor 77: 488-492.

Hussell, D.J.T. (1988). Supply and demand in Tree Swallow broods: a model of parent offspring food-provisioning interactions in birds. - Am. Nat. 131: 175-202.

Iacovides, S. \& Evans, R.M. (1998). Begging as graded signals of need for food in young ring-billed gulls. - Anim. Behav. 56: 79-85.

Kingery, H.E. (1996). American Dipper (Cinclus mexicanus). - In: The Birds of North America, No. 229 (Poole, A. \& Gill, F., eds). The Academy of Natural Sciences, Philadelphia, PA, and The American Ornithologists' Union, Washington, DC.

Kilner, R. (1995). When do canary parents respond to nestling signals of need? - Proc. R. Soc. Lond. B 260: 343-348.

Kolliker, M., Richner, H., Werner, I. \& Heeb, P. (1998). Begging signals and biparental care: nestling choice between parental feeding locations. - Anim. Behav. 55: 215-222.

Krebs, E.A. (2000). Food allocation in crimson rosella broods: parents differ in their responses to chick hunger. - Anim. Behav. 59: 739-751.

Krebs, E.A. (2001). Begging and food distribution in crimson rosella (Platycercus elegans) broods: why don't hungry chicks beg more? - Behav. Ecol. Sociobiol. 50: 20-30.

Langen, T.A. (1996). Skill acquisition and the timing of natal dispersal in the white-throated magpie-jay, Calocitta formosa. - Anim. Behav. 51: 575-588.

Legge, S., Heinsohn, R., Double, A.C., Griffiths, R. \& Cockburn, A. (2001). Complex sex allocation in the laughing kookaburra. - Behav. Ecol. 12: 524-533.

Leonard, M.L., Horn, A.G. \& Ratcliffe, L.M. (1990). Parental aggression in Black-capped chickadees. - Behav. Ecol. 2: 228-233.

Leonard, M.L., Teather, K.L., Horn, A.G., Koenig, W.D. \& Dickinson, J.L. (1994). Provisioning in western bluebirds is not related to offspring sex. - Behav. Ecol. 5: 455-459.

Leonard, M.L. \& Horn, A.G. (1996). Provisioning rules in tree swallows. - Behav. Ecol. Sociobiol. 38: 341-347.

Leonard, M.L. \& Horn, A.G. (1998). Need and nestmates affect begging in tree swallows. Behav. Evol. Sociobiol. 42: 431-436.

Leonard, M.L., Horn, A.G., Gozna, A. \& Ramen, S. (2000). Brood size and begging intensity in nestling birds. - Behav. Ecol. 11: 196-201.

Leonard, M.L. \& Horn, A.G. (2001b). Begging calls and parental feeding decisions in tree swallows (Tachycineta bicolor). — Behav. Ecol. Sociobiol. 49: 170-175.

Marchetti, K. \& Price, T. (1989). Difference in the foraging of juvenile and adult birds: the importance of developmental constraints. - Biol. Rev. 64: 51-70. 
McCutchen, N.A. (2002). The response of stonefly (Plecoptera) nymphs to seasonal increases in predation risk. - Can. J. Zool. 80: 967-972.

Moreno, J. (1984). Parental care of fledged young, division of labor, and the development of foraging techniques in the Northern Wheatear (Oenanthe oenanthe). - Auk 101: 741-752.

Morrissey, C.A. (2004). Effect of altitudinal migration within a watershed on the reproductive success of American dippers. - Can. J. Zool. 82: 800-807.

Neuenschwander, S., Brinkhof, M.W.G., Kolliker, M. \& Richner, H. (2003). Brood size, sibling competition, and the cost of begging in great tits (Parus major). - Behav. Ecol 14: 457-462.

Payne, R.W. (2006). The Guide to Genstat Release 8. - VSN International, Oxford, UK.

Phillips, R.A. \& Croxall, J.P. (2003). Control of provisioning in grey-headed albatrosses (Thalassarche chrysostoma): do adults respond to chick condition? - Can. J. Zool. 81: 111-116.

Price, K. \& Ydenberg, R. (1995). Begging and provisioning in broods of asynchronouslyhatched yellow-headed blackbird nestlings. — Behav. Ecol. Sociobiol. 37: 201-208.

Price, K., Harvey, H. \& Ydenberg, R. (1996). Begging tactics of nestling yellow-headed blackbirds, Xanthocephalus xanthocephalus, in relation to need. - Anim. Behav. 51: 421-435.

Redondo, T. \& Castro, F. (1992a). Signalling of nutritional need by Magpie nestlings. Ethology 92: 193-204.

Redondo, T. \& Castro, F. (1992b). The increase in predation with begging activity in broods of magpies (Pica pica). - Ibis 134: 180-187.

Ryden, O. \& Bengtsson, H. (1980). Differential begging and locomotory behaviour by early and late hatched nestlings affecting the distribution of food in asynchronously hatched broods of altricial birds. - Z. Tierpsychol. 53: 209-224.

Sacchi, R., Saino, N. \& Galeotti, P. (2002). Features of begging calls reveal general condition and need of food of barn swallow (Hirundo rustica) nestlings. - Behav. Ecol. 13: 268273.

Sasvári, L. (1990). Feeding response of mated and widowed bird parents to fledglings: an experimental study. — Ornis. Scand. 21: 287-292.

Smiseth, P.T., Amundsen, T. \& Hansen, L.T.T. (1998). Do males and females differ in the feeding of large and small siblings? An experiment with the bluethroat. - Behav. Ecol. Sociobiol. 42: 321-328.

Smiseth, P.T., Bu, R.J., Eikenæs, A.K. \& Amundsen, T. (2003). Food limitation in asynchronous bluethroat broods: effects on food distribution, nestling begging, and parental provisioning rules. - Behav. Ecol. 14: 793-801.

Smith, H.G. \& Montgomerie, R. (1991). Nestling American robins compete with siblings by begging. - Behav. Ecol. Sociobiol. 29: 307-312.

Smith, T.E., Leonard, M.L. \& Smith, B.D. (2005). Provisioning rules and chick competition in asynchronously hatching common terns (Sterna hirundo). - Behav. Ecol. Sociobiol. 58: 456-465.

Stamps, J., Clark, A., Arrowood, P. \& Kus, B. (1989). Parent-offspring conflict in budgerigars. - Ethology 81: 177-192.

Sullivan, K.A. (1988). Ontogeny of time budgets in yellow-eyed juncos: adaptation to ecological constraints. - Ecology 69: 118-124.

Trivers, R.L. (1974). Parent-offspring conflict. — Am. Zool. 14: 249-263. 
Copyright of Behaviour is the property of VSP International Science Publishers and its content may not be copied or emailed to multiple sites or posted to a listserv without the copyright holder's express written permission. However, users may print, download, or email articles for individual use. 